This Section of Epidemiology and Psyhiartric Science regularly appears in each issue of the Journal to describe relevant studies investigating the relationship between neurobiology and psychosocial psychiatry in major psychoses.The aim of these Editorials is to provide a better understanding of the neural basis of psychopathology and clinical features of these disorders, in order to raise new perspectives in every-day clinical practice.

Paolo Brambilla, Section Editor and Michele Tansella, Editors EPS

\title{
Functional MRI studies in disruptive behaviour disorders
}

\author{
M. Bellani ${ }^{1 *}$, M. Garzitto ${ }^{2}$ and P. Brambilla ${ }^{3,4}$ \\ ${ }^{1}$ Section of Psychiatry and Clinical Psychology, Department of Public Health and Community Medicine, Inter-University Center for Behavioural \\ Neurosciences (ICBN), University of Verona, Verona, Italy \\ 2 Department of Human Sciences, University of Udine, Udine, Italy \\ ${ }^{3}$ Department of Experimental Clinical Medicine, Inter-University Center for Behavioural Neurosciences (ICBN), University of Udine, Udine, Italy \\ ${ }^{4}$ IRCCS 'E. Medea' Scientific Institute, Udine, Italy
}

\begin{abstract}
Aggressive or antisocial behaviours with violations of social rules are the main features of disruptive behaviour disorders (DBDs), which are developmental diseases and include conduct disorder and oppositional defiant disorder. In the last decade, several efforts have been made to shed light on the biological underpinnings of DBDs. In this context, the main findings of functional magnetic resonance imaging studies in DBD are reported here. There are indications of neural dysfunctions in response to affective stimuli, especially regarding medial and orbitofrontal prefrontal cortex and connected subcortical structures.
\end{abstract}

Received 15 September 2011; Revised 20 September 2011; Accepted 25 September 2011

Key words: Disruptive behaviour disorders, adolescents, fMRI.

Disruptive behaviour disorders (DBDs) are common and severe developmental disorders include conduct disorder (CD) and oppositional defiant disorder (ODD). They are characterized by aggressive and antisocial behaviours associated with violations of social rules (e.g. thefts and violent behaviour) and are considered a predictor of antisocial/borderline personality disorder and substance abuse (Schutter et al. 2011). Also, they are more common in boys than in girls and are associated with a lower quality of life (Bot et al. 2011). High comorbidity is usually observed with attention deficit hyperactivity disorder (ADHD) (Spencer, 2006; Bellani et al. 2011). It should be noted

* Address for correspondence: Dr M. Bellani, Section of Psychiatry and Clinical Psychology, Department of Public Health and Community Medicine, University of Verona, Piazzale L.A. Scuro 10, 37134 Verona, Italy.

(Email: marcella.bellani@univr.it; paolo.brambilla@uniud.it) that DBD children and preadolescents with comorbid ADHD show higher use of mental health services than those with mood or anxiety disorders and that ODD diagnosis is associated with the highest likelihood of the use of services at the age of 14-15 years (Ezpeleta et al. 2009). Recently, interest was addressed to a sub-group of DBDs with the so-called callous-unemotional traits (i.e. reduced empathy and guilt, poor emotional response), which may be associated with increased risk of antisocial outcomes (Marsh et al. 2008; De Brito et al. 2009).

Several functional magnetic resonance imaging (fMRI) studies have been conducted so far to explore the biological bases of DBDs (Table 1). Specifically, adolescents with DBD exposed to emotional pictures (i.e. negative/painful situations and fearful/sad faces) showed enhanced activation of amygdala, striatum, mid-cingulate and orbitofrontal cortex (OFC) (Herpertz et al. 2008; Decety et al. 2009; Passamonti 
Table 1. $f M R I$ studies in DBDs using affective stimuli

\begin{tabular}{|c|c|c|c|c|}
\hline Study & Subjects & Age range (years) & fMRI stimuli (pictures) & Findings in DBDs \\
\hline $\begin{array}{l}\text { Sterzer et al. } \\
\text { (2005) }\end{array}$ & 13: CD; 14: HS & $9-15$ & $\begin{array}{l}\text { Strong negative emotional } \\
\text { valence; neutral. }\end{array}$ & $\begin{array}{l}\text { Negative stimuli: deactivation in } \\
\text { right dorsal ACC. }\end{array}$ \\
\hline $\begin{array}{l}\text { Marsh et al. } \\
\quad(2008)\end{array}$ & $\begin{array}{r}\text { 12: } 8 \text { CUT-ODD; } \\
4 \text { CUT-CD; 12: } \\
\text { ADHD; 12: HS }\end{array}$ & $10-17$ & $\begin{array}{l}\text { Fearful faces; angry faces; } \\
\text { neutral faces. }\end{array}$ & $\begin{array}{l}\text { Fearful faces: less activation in left } \\
\text { amygdala; less correlation between } \\
\text { activities in right amygdala and } \\
\text { ventromedial PFC. }\end{array}$ \\
\hline $\begin{array}{l}\text { Herpertz et al. } \\
\text { (2008) }\end{array}$ & $\begin{array}{l}\text { 22: CD (22: HS); } \\
\text { 13: ADHD (13: HS) }\end{array}$ & $12-17$ & $\begin{array}{l}\text { Highly arousing negative; } \\
\text { arousing positive; } \\
\text { neutral. }\end{array}$ & $\begin{array}{l}\text { Negative stimuli: more activation in } \\
\text { left amygdala. }\end{array}$ \\
\hline $\begin{array}{l}\text { Jones et al. } \\
\text { (2009) }\end{array}$ & 17: CUT; 13: HS & $10-12$ & $\begin{array}{l}\text { Pictures: fearful faces; } \\
\text { neutral faces. }\end{array}$ & $\begin{array}{l}\text { Fearful faces: less activation in right } \\
\text { amygdala. }\end{array}$ \\
\hline $\begin{array}{l}\text { Decety et al. } \\
\text { (2009) }\end{array}$ & 8: CD; 8: HS & $\begin{array}{r}\text { 16-18 (longitudinal } \\
\text { evaluation: 9-18) }\end{array}$ & $\begin{array}{l}\text { Painful situations } \\
\text { (accidentally or } \\
\text { intentionally caused); } \\
\text { non-painful situations. }\end{array}$ & $\begin{array}{l}\text { Accidentally caused painful situation: } \\
\text { stronger signal response of anterior } \\
\text { MCC, striatum, left amygdala. } \\
\text { Intentionally caused painful } \\
\text { situation: activation in medial OFC. }\end{array}$ \\
\hline $\begin{array}{l}\text { Passamonti } \\
\text { et al. (2010) }\end{array}$ & $\begin{array}{l}\text { 20: EO-CD; 20: } \\
\text { AO-CD; 20: HS }\end{array}$ & $16-21$ & $\begin{array}{l}\text { Sad faces; angry faces; } \\
\text { neutral faces. }\end{array}$ & $\begin{array}{l}\text { Angry faces: less activation in } \\
\text { amygdala, ventromedial PFC, } \\
\text { OFC, insula. } \\
\text { Sad faces: more activation in } \\
\text { amygdala (only in EO-CD). } \\
\text { Neutral faces: more activation in } \\
\text { amygdala. }\end{array}$ \\
\hline
\end{tabular}

ACC, anterior cingulate cortex; ADHD, attention deficit hyperactivity disorder; $\mathrm{AO}$, adolescent-onset; $\mathrm{CD}$, conduct disorder; CUT, high callous-unemotional traits; EO, early-onset; HS, healthy subjects; MCC, midcinguale cortex; ODD, oppositional defiant disorder; OFC, orbitofrontal cortex; PFC, prefrontal cortex.

et al. 2010) and reduced activation of anterior cingulate cortex (ACC) (Sterzer et al. 2005). Also, they had reduced functional connectivity between amygdala and medial prefrontal cortex (Marsh et al. 2008; Decety et al. 2009). In two studies, reduced activation of amygdala was instead observed in DBD adolescents with high callous-unemotional traits (Marsh et al. 2008; Jones et al. 2009). Interestingly, a reduced activation of amygdala, insula and PFC was also present in response to angry faces in CD (Passamonti et al. 2010). Such functional abnormalities are consistent with structural alterations showing volume reduction of amygdala, hippocampus, insula, OFC, dorsomedial PFC, temporal cortex and caudate nucleus, particularly in CD children (Huebner et al. 2008; Fairchild et al. 2011). However, increased sizes of medial OFC and dorsal ACC, with preserved amygdala and insula morphometry, have also been found in boys with callous-unemotional traits and conduct problems (De Brito et al. 2009).

Based on the imaging literature briefly summarized above, a dysfunctional network including amygdala, PFC, striatum and insula may underlie affective dysregulation reported in subjects with DBD. In this context, preliminary findings suggest that DBD patients with callous-unemotional traits, particularly those with $\mathrm{CD}$, may represent a specific sub-group with peculiar functional and structural brain maturation. Future fMRI studies should explore whether such abnormalities are specific to CD or ODD (Barker et al. 2011) and whether they persist over time during development. They should also further investigate the role of callous-unemotional traits for brain development in these children and should differentiate the specific features of DBD and ADHD (Rubia, 2011).

\section{References}

Barker ED, Tremblay RE, van Lier PAC, Vitaro F, Nagin DS, Assaad J, Séguin JR (2011). The neurocognition of conduct disorder behaviors: specificity to physical aggression and theft after controlling for ADHD symptoms. Aggressive Behavior 37, 63-72.

Bellani M, Moretti A, Perlini C, Brambilla P (2011). Language disturbances in ADHD. Epidemiology and Psychiatric Sciences 20, 311-315.

Bot M, de Leeuw den Bouter BJE, Adriaanse MC (2011). Prevalence of psychosocial problems in Dutch children 
aged 8-12 years and its association with risk factors and quality of life. Epidemiology and Psychiatric Sciences 20, 1-9.

De Brito SA, Mechelli A, Wilke M, Laurens KR, Jones AP, Barker GJ, Hodgins S, Viding E (2009). Size matters: increased grey matter in boys with conduct problems and callous-unemotional traits. Brain 132, 843-852.

Decety J, Michalska KJ, Akitsuki Y, Lahey BB (2009). Atypical empathic responses in adolescents with aggressive conduct disorder: a functional MRI investigation. Biological Psychology 80, 203-211.

Ezpeleta L, Granero R, de la Osa N, Domènech JM (2009). Use of mental health services and unmet needs for socially-at-risk. Spanish children and adolescents. Epidemiology and Psychiatric Sciences 18, 147-153.

Fairchild G, Passamonti L, Hurford G, Hagan CC, von dem Hagen EAH, van Goozen SHM, Goodyer IM, Calder AJ (2011). Brain structure abnormalities in early-onset and adolescent-onset conduct disorder. American Journal of Psychiatry 168, 624-633.

Herpertz SC, Huebner T, Marx I, Vloet TD, Fink GR, Stoecker T, Shah NJ, Konrad K, Herpertz-Dahlmann B (2008). Emotional processing in male adolescents with childhood-onset conduct disorder. Journal of Child Psychology and Psychiatry 49, 781-791.

Huebner T, Vloet TD, Marx IM, Konrad K, Fink GR, Herpertz SC, Herpertz-Dahlmann B (2008). Morphometric brain abnormalities in boys with conduct disorder. Journal of the American Academy of Child and Adolescent Psychiatry 47, 540-547.
Jones AP, Laurens KR, Herba CM, Barker GJ, Viding E (2009). Amygdala hypoactivity to fearful faces in boys with conduct problems and callous-unemotional traits. American Journal of Psychiatry 166, 95-102.

Marsh AA, Finger EC, Mitchell DGV, Reid ME, Sims C, Kosson DS, Towbin KE, Leibenluft E, Pine DS, Blair RJR (2008). Reduced amygdala response to fearful expressions in children and adolescents with callous-unemotional traits and disruptive behavior disorders. American Journal of Psychiatry 165, 712-720.

Passamonti L, Fairchild G, Goodyer IM, Hurford G, Hagan CC, Rowe JB, Calder AJ (2010). Neural abnormalities in early-onset and adolescence-onset conduct disorder. Archives of General Psychiatry 67, 729-738.

Rubia K (2011). "Cool" inferior frontostriatal dysfunction in attention-deficit/hyperactivity disorder versus "hot" ventromedial orbitofrontal-limbic dysfunction in conduct disorder: a review. Biological Psychiatry 69, e69-e87.

Schutter DJLG, van Bokhoven I, Vanderschuren LJMJ, Lochman JE, Matthys W (2011). Risky decision making in substance dependent adolescents with a disruptive behavior disorder. Journal of Abnormal Child Psychology 39, 333-339.

Spencer TJ (2006). ADHD and comorbidity in childhood. Journal of Clinical Psychiatry 67, 27-31.

Sterzer P, Stadler C, Krebs A, Kleinschmidt A, Poustka F (2005). Abnormal neural responses to emotional visual stimuli in adolescents with conduct disorder. Biological Psychiatry 57, 7-15. 